\title{
Impaired Adult Neurogenesis Associated with Short-Term Memory Defects in NF- $\kappa$ B p50-Deficient Mice
}

\author{
Suzanne Denis-Donini, ${ }^{1,2 *}$ Anna Dellarole, ${ }^{3,4 *}$ Paola Crociara, ${ }^{3,4}$ Maria Teresa Francese, ${ }^{3,4}$ Valeria Bortolotto, ${ }^{3,4}$ \\ Giorgia Quadrato, ${ }^{3,4}$ Pier Luigi Canonico, ${ }^{3,4}$ Marco Orsetti, ${ }^{3,4}$ Piera Ghi, ${ }^{5}$ Maurizio Memo, ${ }^{6}$ Sara Anna Bonini, ${ }^{6}$ \\ Giulia Ferrari-Toninelli, ${ }^{6}$ and Mariagrazia Grilli ${ }^{3,4}$ \\ ${ }^{1}$ Department of Biology, Section of Zoology and Cytology, University of Milan and 2Neuroscience Institute, National Research Council, Milan 20100, Italy, \\ ${ }^{3}$ Department of Chemical, Food, Pharmaceutical, and Pharmacological Sciences (DiSCAFF), University of Piemonte Orientale "A. Avogadro" and 4 Drug and \\ Food Biotechnology Center, Novara 28100, Italy, ${ }^{5}$ Department of Anatomy, Pharmacology and Forensic Medicine, University of Turin, Turin 10125, Italy, \\ and ${ }^{6}$ Department of Biomedical Sciences and Biotechnologies, University of Brescia, Brescia 25100, Italy
}

Neurogenesis proceeds throughout adulthood in the brain of most mammalian species, but the molecular mechanisms underlying the regulation of stem/progenitor cell proliferation, survival, maturation, and differentiation have not been completely unraveled. We have studied hippocampal neurogenesis in NF- $\kappa \mathrm{B}$ p50-deficient mice. Here we demonstrate that in absence of p50, the net rate of neural precursor proliferation does not change, but some of the steps leading to the final neuron differentiation status are hampered, resulting in $\sim 50 \%$ reduction in the number of newly born neurons in the adult mutant hippocampus. Additionally, in p50 ${ }^{-I-}$ mice, we observed a selective defect in short-term spatial memory performance without impairment of hippocampal-dependent spatial long-term memory and learning. Our results highlight the role of NF- $\kappa \mathrm{B}$ p50 in hippocampal neurogenesis and in short-term spatial memory.

Key words: NF- $\kappa$ B; neurogenesis; hippocampus; memory; calretinin; doublecortin

\section{Introduction}

Neurogenesis proceeds throughout adulthood in two discrete brain regions, the subventricular zone (SVZ) of the lateral wall of the lateral ventricle and the subgranular zone (SGZ) of the dentate gyrus (DG) in the hippocampal region. Although the role of adult neurogenesis remains to be fully elucidated, several studies have correlated changes in hippocampal neurogenesis with altered performance of hippocampus-dependent learning tasks, thus suggesting that ongoing neurogenesis in adulthood could be involved in functions such as memory and learning (Kempermann et al., 1997, 2004; Gould et al., 1999; Shors et al., 2001; Aimone et al., 2006).

The events that contribute to hippocampal postnatal neurogenesis rely on the maintenance and proliferation of multipotent stem/progenitor cells located in the SGZ niche, a permissive and instructive microenvironment where stem cells survive throughout life, self-renew, and give rise, by asymmetric division, to precursor cells, which then migrate into the adjacent granule cell layer. Only a small proportion of these committed precursors survive and differentiate into neurons, whereas the majority die (Biebl et al., 2000). Adult-generated newborn neurons extend

Received Jan. 13, 2008; revised Feb. 20, 2008; accepted March 5, 2008.

This work was supported by grants from Fondazione Cariplo and from Regione Piemonte, Ricerca Scientifica Applicata CIPE 2004 and Ricerca Sanitaria Finalizzata (M.G.)

*S.D.-D. and A.D. contributed equally to this work.

Correspondence should be addressed to Prof. Mariagrazia Grilli, Laboratory of Neuroplasticity and Pain, Department of Chemical, Food, Pharmaceutical, and Pharmacological Sciences (DiSCAFF) and Drug and Food Biotechnology Center, Via Bovio 6, 28100 Novara, Italy. E-mail: grilli@pharm.unipmn.it.

DOI:10.1523/JNEUROSCI.0148-08.2008

Copyright $\odot 2008$ Society for Neuroscience $\quad$ 0270-6474/08/283911-09\$15.00/0 axons and dendrites and are integrated into the preexisting functional network (Kempermann et al., 2004; Lehmann et al., 2005). In summary, net adult neurogenesis results from the complex interplay of cell proliferation, death, migration, and differentiation, and the molecular pathways that underlie these cellular processes are obviously multifaceted.

We previously demonstrated the presence of distinct NF- $\kappa \mathrm{B}$ family members in specific cell populations of the neurogenic SVZ region of the adult brain (Denis-Donini et al., 2005), thus suggesting their contribution to signaling pathways operative in postnatal neurogenesis. However, a role for NF- $\kappa \mathrm{B}$ in the generation, survival, and differentiation of new neurons remains to be demonstrated in vivo. In the SGZ of the dentate gyrus, close interactions of putative stem cells with transient precursor cells have been observed, suggesting that primary progenitors continue to interact closely with their progeny, possibly exchanging signals that are important for their differentiation and maturation (Seri et al., 2001, 2004; Kempermann et al., 2004). In such respect, NF- $\kappa$ B proteins represent ideal candidates for translating signals in the highly specialized neurogenic niche. Furthermore, NF- $\kappa$ B proteins exhibit major and opposed functions in neurons, because they can both promote and protect against cell death (Grilli et al., 1996; Denk et al., 2000; Mattson and Camandola, 2001; Mattson and Meffert, 2006), substantiating the hypothesis that they could play roles in the control of the net rate of neurogenesis. To gain insight into the role of specific subunits of the $\mathrm{NF}-\kappa \mathrm{B} /$ Rel family in adult hippocampal neurogenesis, we have taken advantage of the availability of mice carrying a homozygous deletion of the NF- $\kappa \mathrm{B} 1$ gene encoding the p50 subunit (Sha et al., 1995), which have been shown to develop normally and do 
not present anomalies in brain architecture and morphology. In this study, we compared hippocampal progenitor proliferation, survival, and differentiation in $\mathrm{p}^{-1-}$ and wild-type (wt) mice. Additionally, mutant and wt animals were analyzed for their cognitive performance in hippocampal-dependent learning and memory tasks.

\section{Materials and Methods}

Animals. NF- $\kappa \mathrm{B} \mathrm{p} 50^{-1-}$ mice (B6;129P2-Nfkb1tm1Bal/J) and wild-type mice (B6;129PF2) were purchased from The Jackson Laboratories (Bar Harbor, ME). Only male, age-matched (3-4 months of age) $\mathrm{p}^{-1-}$ and wt mice were used for our studies. All mice were maintained in highefficiency particulate air-filtered Thoren units (Thoren Caging Systems, Hazleton, PA) at the University of Piemonte Orientale animal facility, were kept three to four per cage, and had ad libitum access to water and food. All of the animal treatments were performed in accordance with the National Institutes of Health guidelines and also reviewed and approved by the local Institutional Animal Care and Use Committee.

Tissue preparation. Mice were deeply anesthetized with Avertin and perfused transcardially with saline, followed by $4 \%$ paraformaldehyde (PFA) in $0.1 \mathrm{~m}$ phosphate buffer (PB), $\mathrm{pH} 7.4$, at $4^{\circ} \mathrm{C}$; their brains were removed, postfixed in $4 \%$ PFA, and then immersed in $30 \%$ sucrose $/ 0.1 \mathrm{M}$ $\mathrm{PB}$. Tissue was cut sagittally or frontally as $40-\mu \mathrm{m}$-thick sections, which were stored at $-20^{\circ} \mathrm{C}$ in a cryoprotectant solution until used.

Bromodeoxyuridine treatment and immunohistochemistry. Mice were injected intraperitoneally once or for 5 consecutive days with bromodeoxyuridine (BrdU; $150 \mathrm{mg} / \mathrm{kg}$ body weight) and killed $2 \mathrm{~h}, 24 \mathrm{~h}$, or $21 \mathrm{~d}$ after the last injection. For BrdU detection, DNA was denatured by pretreating the sections with $2 \mathrm{~N} \mathrm{HCl}$ for $30 \mathrm{~min}$ at $37^{\circ} \mathrm{C}$, followed by washes in $0.1 \mathrm{~m}$ borate buffer, $\mathrm{pH} 8.5$, for $10 \mathrm{~min}$. For Ki67 staining, sections were mounted on Superfrost slides, dried for $2 \mathrm{~h}$, and antigen unmasked with the Target Retrieval solution (DakoCytomation, Glostrup, Denmark) for 30 min at $98^{\circ} \mathrm{C}$. After blocking peroxidase activity with $0.3 \% \mathrm{H}_{2} \mathrm{O}_{2}$ for 15 min, sections were washed, incubated in blocking buffer ( $5 \%$ normal serum, $0.3 \%$ Triton $\mathrm{X}-100$ in TBS) for $1 \mathrm{~h}$ at $4^{\circ} \mathrm{C}$, and then incubated with rat monoclonal anti-BrdU (1:200; Novus Biologicals, Littleton, CO) or rat monoclonal antibody against Ki67 (1:150; DakoCytomation) or rabbit anti-calretinin (CR) antibody (1:4000; Swant, Bellinzona, Switzerland) or goat anti-doublecortin (DCX) antibody (1:1000; Santa Cruz Biotechnology, Santa Cruz, CA) in TBS-plus (TBS containing 0.1\% Triton $\mathrm{X}-100$ and $2 \%$ normal serum) overnight at $4^{\circ} \mathrm{C}$. Sections were washed in TBS-Tween $0.1 \%$ and incubated with the biotinylated rabbit anti-rat, goat anti-rabbit, or horse anti-goat secondary antibody (1:200; Vector Laboratories, Burlingame, CA) for $1.5 \mathrm{~h}$ at $4^{\circ} \mathrm{C}$. Labeled cells were visualized using the $\mathrm{ABC}$ system (Vectastain Elite; Vector Laboratories) with 3,3'-diaminobenzidine as chromogen. The sections were then mounted onto poly-lysine-coated slides, counterstained with hematoxylin (Vector Laboratories), dehydrated, and coverslipped with DPX. For NeuN and BrdU double-labeling immunofluorescence, free-floating sections were incubated with mouse anti-NeuN primary antibody (1:100; Millipore, Billerica, MA) overnight at $4^{\circ} \mathrm{C}$. The next day, the sections were washed with TBS-Tween and incubated with biotinylated horse anti-mouse antibody (1:200; Vector Laboratories) for $1.5 \mathrm{~h}$ at $4^{\circ} \mathrm{C}$, rinsed, and incubated for $1 \mathrm{~h}$ in Texas Red Streptavidin (1:100; Vector Laboratories). Then the sections were washed, denatured by $2 \mathrm{~N} \mathrm{HCl}$, rinsed, and incubated with rat anti-BrdU overnight at $4^{\circ} \mathrm{C}$. The following day, the sections were incubated with secondary antibody (CY2 goat anti-rat; 1:200; Jackson ImmunoResearch, West Grove, PA). After several washes, the sections were mounted onto Superfrost slides and coverslipped with Fluorescent Mounting Medium (DakoCytomation) as anti-fading agent.

Quantification and phenotype of newborn cells. For quantification of BrdU, Ki67, DCX, and CR labeling, a modified unbiased stereology protocol was used specifically confirming that each labeled cell was counted only once and that the area counted was consistent across all sections. For each animal, a complete series of one-in-eight sections (320 $\mu \mathrm{m}$ apart) through the dentate gyrus was analyzed, and positive cells were counted using a $60 \times$ objective throughout the rostrocaudal extent of the dentate gyrus. The optical dissector method was modified in that cells appearing in the uppermost focal plane were not counted, as described previously (West, 1999; Kempermann et al., 2003). The counting procedure for the dentate gyrus was as follows: SGZ was defined as two cell bodies wide of the hilus along the border of the granule cell layer, and cells were qualified as being in the SGZ if they were touching or were within the SGZ. Hilar cells were counted only if they were more than two cells away from the SGZ. The cell counts from each section were added and multiplied by 8 to obtain the total number of labeled cells in the dentate gyrus for each brain. To determine the percentage of neuronal differentiation of newborn cells, a series of every eighth section was stained for double immunofluorescence with antibodies against BrdU and NeuN, as described above. An average of $8-10$ sections per animal was used. For each brain, $100 \mathrm{BrdU}$-immunopositive cells were randomly selected within the granule cell layer and analyzed for BrdU/NeuN double labeling. Fluorescent signals were detected using a confocal scanning laser microscope (Leica TCS-NT; Leica Lasertechnik, Heidelberg, Germany) and a 60× PL APO oil objective (1.25 numerical aperture). To exclude false-positive signals from overlying cells, pinhole settings were used that corresponded to an optical thickness of $<2 \mu \mathrm{m}$. Each BrdU cell was analyzed in its entire $z$-axis to exclude a false double labeling resulting from an overlay of signals from different cells. Only those cells for which the BrdU-positive nucleus was unambiguously associated with the lineage-specific marker were scored as positive.

TUNEL evaluation. Apoptosis was analyzed by in situ terminal deoxynucleotidyl transferase-mediated dUTP nick-end labeling (TUNEL) using the ApoTag Red In Situ Apoptosis Detection Kit (Millipore) according to the manufacturer's instructions. To determine the number of TUNEL-positive cells in the granule cell layer (GCL) of the hippocampus, every sixth brain section ( $40 \mu \mathrm{m}$ thick, $240 \mu \mathrm{m}$ intervals) was selected from each animal ( $n=6 /$ genotype) and processed for TUNEL assay. Positive cells were counted in every section from rostral to caudal throughout the hippocampus (10 sections for each individual animal) using the dissector method. Positive profiles that intersected the uppermost focal plane (exclusion plane) were not counted. The volume of the dentate gyrus was determined on tissue stained with toluidine blue by using a semiautomatic stereology system LSM 510 Meta Software Analyser software (Carl Zeiss MicroImaging, Thornwood, NY) that employs the Cavalieri method. Data were expressed as number of total positive cells $/ \mathrm{mm}^{3}$ of DG.

Western blot analysis. Protein extracts were prepared from the hippocampi of 3-month old wt and $\mathrm{p}^{-1-}$ mice. Western blotting was performed using $6-12 \%$ SDS polyacrylamide gels with $25 \mu \mathrm{g}$ of protein extract loaded per lane. Nitrocellulose filters were incubated with primary antibodies raised against DCX, calretinin, synaptophysin, and MAP2 overnight at $4^{\circ} \mathrm{C}$, followed by peroxidase-conjugated secondary antibodies. Gels were stripped and reprobed with anti- $\alpha$-tubulin. Densitometric analysis was performed using the Quantity One software system (Bio-Rad Laboratories, Hercules, CA) and each band was normalized to the $\alpha$-tubulin signal in each lane.

Isolation and culture of adult hippocampal neurospheres. For each neurosphere preparation, three adult (3-4 months of age) $\mathrm{p}^{-1-}$ and wt male mice were killed by cervical dislocation. The brains were removed, and hippocampi were isolated under a dissecting microscope, in ice-cold PIPES buffer, pH 7.4, containing $20 \mathrm{~mm}$ PIPES, $25 \mathrm{~mm}$ glucose, $0.5 \mathrm{M} \mathrm{KCl}$, and $0.12 \mathrm{M} \mathrm{NaCl}$. After centrifugation $(5 \mathrm{~min}$ at $110 \times \mathrm{g}$ ), tissue was digested for $5 \mathrm{~min}$ at $37^{\circ} \mathrm{C}$ with $0.25 \%$ trypsin (Sigma, St. Louis, MO) and mechanically dissociated. Single-cell suspension was collected by centrifugation $(10 \mathrm{~min}$ at $110 \times \mathrm{g})$, plated in a T25 flask (Falcon BD, Franklin Lakes, NJ) and cultured in Neurobasal-A medium (Invitrogen, Carlsbad, CA) containing B27 supplement (Invitrogen), basic fibroblast growth factor-2 (bFGF-2; $10 \mathrm{ng} / \mathrm{ml}$; PeproTech, Rocky Hill, NJ), epidermal growth factor (EGF; $20 \mathrm{ng} / \mathrm{ml}$, Sigma), and heparin sodium salt (0.0004\%; Sigma). For proliferation assays, neurospheres at passages $4-8$ were dissociated and plated at a density of $1 \times 10^{5}$ cells $/ \mathrm{ml}$ in 96 -well plates. At 24, 48, 72, and $96 \mathrm{~h}$ after plating, samples were processed for detection of the amount of cellular ATP using the CellTiter-Glow Luminescent kit (Promega, Madison, WI), according to the manufacturer's instructions. All experiments were run in quadruplicates, in three differ- 
ent cell preparations, and data were expressed as percentage increase over ATP content at plating time.

Behavioral tests. Male mice (3-4 months of age; $15-16$ per group of each genotype) were used for behavioral evaluation. Short-term spatial memory was evaluated in the place recognition test by testing the ability of the mice to discriminate a familiar versus a novel environment. The Y-maze was placed in a sound-isolated room equipped with a constant illumination, and several visual cues were placed near the maze and kept constant during all the experiments. The test consisted of two trials, separated by different retention intervals. In the first trial, one arm of the maze was closed with a guillotine door, and mice were allowed to visit the other two open arms for $10 \mathrm{~min}$. During the second trial, mice had ad libitum access to the three arms and were allowed to explore the maze for $5 \mathrm{~min}$. At the beginning of both trials, each mouse was placed in the same arm and was oriented in the opposite direction to the center of the maze. In our experimental setting, the entry arm was changed randomly to reduce the influence of external cues on animal performance. Similarly, the position of the novel arm (the arm closed by the guillotine door in the training trial) was kept in a random order at the left for half the mice and at the right of the entry arm for the other half. After each trial, the maze was carefully cleaned to eliminate olfactory stimuli. The dependent variables measured in the testing trial were the number of entries made into each arm to determine spatial memory and the total entries into each arm to determine locomotion. A visit was recorded only when the mouse entered with its four paws the rectangular space $(8 \times 15 \mathrm{~cm})$ representing the distal half of the arm. Long-term spatial memory was evaluated in mice by the Morris water maze task. The maze (black plastic; diameter, $100 \mathrm{~cm} ; 60 \mathrm{~cm}$ deep) filled up with water $\left(25 \pm 1^{\circ} \mathrm{C}\right)$ to a depth of $40 \mathrm{~cm}$, and surrounded by several proximal and distal visual cues. After a single adaptation trial (day $0,90 \mathrm{~s}$, no platform), on the following day a submerged escape platform ( $1 \mathrm{~cm}$ below the water level, $10 \mathrm{~cm}$ diameter) was placed in the middle of one of four virtual quadrants, and mice were trained in a 1 trial/d task for 10 consecutive days. The platform was located in the quadrant that was not preferred or avoided by the mice during the adaptation trial. Each day, the animals were lowered into the pool from three different starting points (left, opposite, and right of the platform quadrant) in a random manner. Animals that did not find the escape platform within $60 \mathrm{~s}$ were placed there by the experimenter. All mice remained on the platform for $20 \mathrm{~s}$. For each trial, the escape latency was measured, and the mouse performance was tracked by a video camera. For the spatial probe, the platform was removed, and the time spent in each quadrant during a single trial over $60 \mathrm{~s}$ was registered. In the cued version, used to evaluate whether changes in mouse performance on long-term spatial memory could be attributable to altered sensorimotor ability, the platform was placed to be visible $1 \mathrm{~cm}$ above the water surface. Additionally, the platform was signaled by a cylinder (diameter, $2 \mathrm{~cm}$; height, $4 \mathrm{~cm}$ ) in the quadrant opposite to its initial position. Again, the escape latency was measured, and the mouse performance was tracked by a video camera.

Statistical analysis. For in vitro and ex vivo neurogenesis evaluation, statistical analysis was performed using the unpaired, two-sided $t$ test comparison (Student's $t$ test). The two-sided Student's $t$ test for unpaired data was also used to compare scores of $\mathrm{p} 50^{-1-}$ mice and their wild-type littermates in beam walking, swimming endurance, pole test, and open field (evaluation of spontaneous exploratory activity). To assess the habituation of exploratory activity in the open field, a two-way mixeddesign ANOVA was performed to check the variation between the successive trials (repeated-measures factor) and genotype (independent variable). In the Morris water maze, results were evaluated by a mixeddesign ANOVA both in the acquisition phase (genotype as independent factor and trial day as repeated-measures factor) and in the probe test (genotype as independent factor and quadrant as repeated-measures factor). In the place recognition test, the entries made into each arm of the Y-maze were converted into percentages of total entries made into all three arms. The percentage of entries made into the novel and other arms were used in the following analyses. Differences in spatial memory across groups were evaluated by two-way ANOVA using genotype and retention interval as independent variables. In all conditions, the dependent variable was a difference score (percentage of entries into the novel
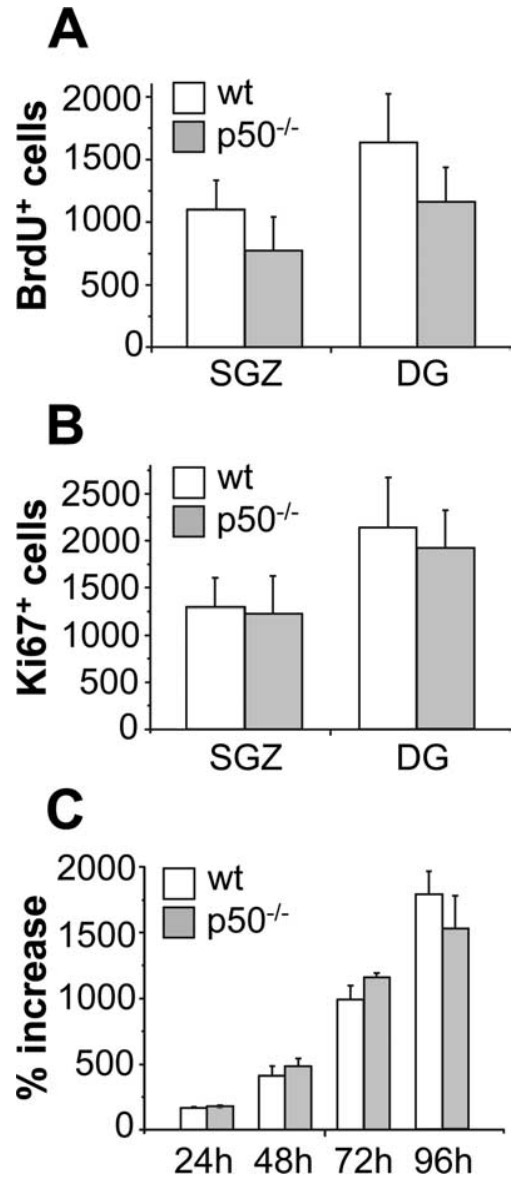

Figure 1. Proliferation of hippocampal progenitor cells is not altered in absence of NF- $\kappa B$ p50. $A, B$ BrdU ${ }^{+}$cells were evaluated in the SGZ and in the entire DG of wt and mutant mice, killed $2 \mathrm{~h}$ after administration of BrdU. $\boldsymbol{B}$, The number of cells immunoreactive for the endogenous proliferation marker Ki67 was determined in the SGZ and in DG of mutant mice and their wt control. Immunohistochemistry data represent mean \pm SD of $n=4-5$ mice per group. $C$, Proliferation rate of hippocampal neural stem cells from wt and $\mathrm{p50}^{-1-}$ mice was evaluated at indicated times after plating in the presence of EGF and bFGF expressed as percentage increase. In vitro data represent mean \pm SEM of three cell preparations, each time point performed in quadruplicates.

arm - percentage of entries into the familiar arm). To further examine whether mice recognize the novel arm for a within-subject comparison, a nonparametric analysis was performed using Wilcoxon test. The percentage of entries into the novel arm was compared with the percentage of entries into the other arms. Mice displaying intact spatial memory will enter the novel arm more than the other arms, whereas animals with impaired spatial memory will enter the novel and other arms similarly. Least significant difference (LSD) post hoc test was used when ANOVA reached significance. Significant differences were assumed at a level of $p<0.05$.

\section{Results}

Proliferation of hippocampal progenitor cells is not altered in p50 ${ }^{-1-}$ mice

Three month-old male $\mathrm{p} 50^{-1-}$ and wt mice $(n=4$ per group) were administered BrdU $150 \mathrm{mg} / \mathrm{kg}$ intraperitoneally and killed $2 \mathrm{~h}$ later, to have an estimate of the cells that are in S-phase in the hippocampal neurogenic regions. BrdU-immunoreactive $\left(\mathrm{BrdU}^{+}\right)$cells were distributed throughout the SGZ and the DG of both genotypes. As expected, the majority of $\mathrm{BrdU}^{+}$cells were located within the SGZ (65-67\%) and the inner half of the GCL (19-24\%), with fewer cells present in the outer half of GCL or in the hilus. The results, shown in Figure $1 A$, did not demonstrate 

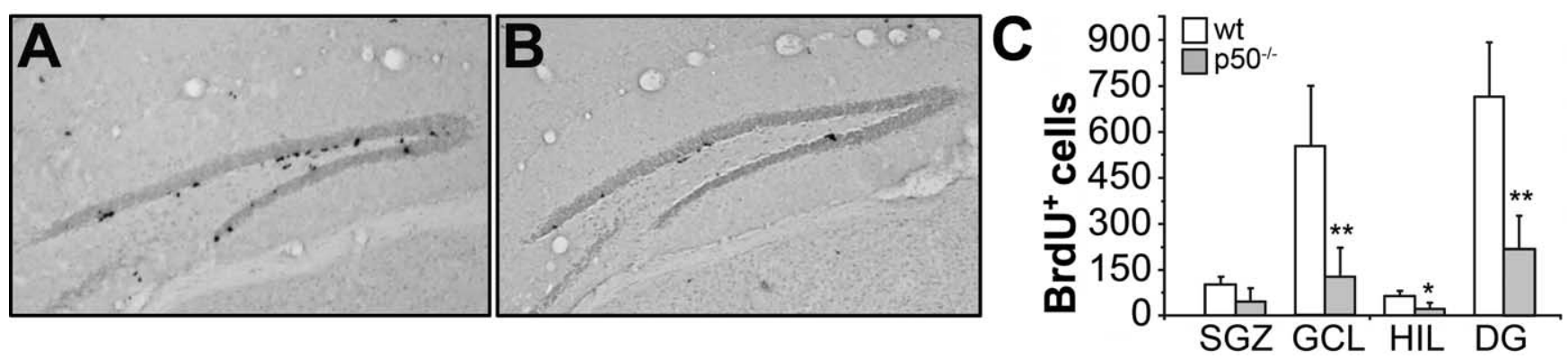

Figure 2. Late survival of BrdU ${ }^{+}$cells is reduced in $\mathrm{p} 50^{-1-}$ mice. $\boldsymbol{A}, \boldsymbol{B}$, BrdU immunostaining in the dentate gyrus of wt $(\boldsymbol{A})$ and p50 ${ }^{-1-}(\boldsymbol{B})$ mice, killed $21 \mathrm{~d}$ after a single BrdU injection. $\boldsymbol{C}$, Quantification of $\mathrm{BrdU}^{+}$cells in subregions of the dentate gyrus [SGZ, GCL, and hilus (HIL)] and in the total dentate gyrus. ${ }^{*} p<0.05 ;{ }^{* *} p<0.01$.

statistically significant difference between wt and mutant mice in the total number of $\mathrm{BrdU}^{+}$cells located in the SGZ (mean number $\pm \mathrm{SD}, 1095 \pm 238$ and $774 \pm 268$ in wt and $\mathrm{p} 50^{-1-}$ mice, respectively; $p=0.123$ ) or in the entire DG (mean number \pm SD, $1635 \pm 391$ and $1162 \pm 276$ in wt and $\mathrm{p} 50^{-1-}$ mice, respectively; $p=0.095)$, suggesting no alteration in the proliferation rate as a result of p50 absence. We also evaluated cell proliferation in the hippocampi of animals killed $24 \mathrm{~h}$ after BrdU injection. Again, the numbers of $\mathrm{BrdU}^{+}$cells in the SGZ and in DG were similar in two genotypes (SGZ, mean number \pm SD, $1274 \pm 90$ and $1135 \pm$ 214 in wt and $\mathrm{p}^{2} 0^{-1-}$ mice, respectively; $p=0.218$; DG, mean number $\pm \mathrm{SD}, 1721 \pm 243$ and $1532 \pm 344$ in wt and p $50^{-1-}$ mice, respectively; $\left.p=0.347\right)$. Similarly, by using the Ki67 endogenous proliferation marker (Scholtzen and Gerdes, 2000), no significant difference was observed between genotypes in the total number of cycling cells, expressed as mean number \pm

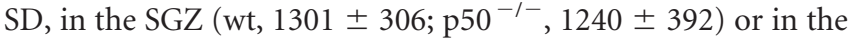
entire dentate gyrus (wt, $2134 \pm 536 ; \mathrm{p} 50^{-/-}, 1917 \pm 403$ ) (Fig. $1 B)$. Additionally, when neurospheres were generated from the hippocampal region of both wt and $\mathrm{p} 50^{-1-}$ mice and their proliferation rate was evaluated, we observed no difference between genotypes (Fig. 1C).

\section{Late survival of $\mathrm{BrdU}^{+}$cells is reduced in $\mathrm{p} 50^{-/-}$mice}

Because after exiting the cell cycle the majority of the newly generated cells in the adult hippocampus die (Biebl et al., 2000), we evaluated the "survival" of BrdU-labeled cells in the dentate gyrus. Animals of both genotypes ( $n=4$ per group) were killed $21 \mathrm{~d}$ after a single BrdU injection ( $150 \mathrm{mg} / \mathrm{kg}$, i.p.). Under these experimental conditions, the total number of $\mathrm{BrdU}^{+}$cells was drastically reduced in $\mathrm{p}^{-1-}$ mice (Fig. $2 \mathrm{~B}$ ) compared with wt mice (Fig. $2 A$ ). The total number of $\mathrm{BrdU}^{+}$cells/hippocampus, expressed as mean $\pm \mathrm{SD}$, was $716 \pm 175.3$ and $215.5 \pm 111.7$ in wt and $550^{-1-}$ mice, respectively ( $p<0.01$, Student's $t$ test) (Fig. $2 C$ ). An analysis of the location of $\mathrm{BrdU}^{+}$cells in the different subregions (SGZ, GCL, and hilus) of the dentate gyrus showed that there was a statistically significant reduction in the number of $\mathrm{BrdU}^{+}$cells in all areas, except in the subgranular zone (Fig. $2 C$ ), possibly suggesting a more pronounced effect of $\mathrm{p} 50$ absence in regions where newly generated cells migrate and differentiate and no significant effect on stem/progenitor cells.

Programmed cell death occurs during normal adult neurogenesis, and increased apoptosis may be one mechanism underlying the reduced survival of $\mathrm{BrdU}^{+}$cells in $\mathrm{p}^{-1-}$ mice. A detailed TUNEL analysis was undertaken in wt and $\mathrm{p}^{-1-}$ mice ( $n=6$ per group) to detect apoptotic cells in the hippocampal region. Ten sections per animal were analyzed, and TUNELpositive cells were counted in the dentate gyrus. TUNEL-positive cells were detected mainly in the SGZ or in the inner half of the granule cell layer. Surprisingly, counts of total numbers of labeled cells revealed that cell death was not significantly different in the two genotypes (mean number of cells $\pm \mathrm{SD} / \mathrm{mm}^{3}$ of dentate gyrus of $130 \pm 13.8$ and $109 \pm 26.7$ in wt and $\mathrm{p}^{-1-}$ mice, respectively; $p=0.115$ ), demonstrating that increased apoptosis cannot account for the reduced number of $\mathrm{BrdU}^{+}$cells in mutant mice 3 weeks after tracer injection.

The absolute number of newly generated neurons is markedly reduced in $\mathrm{p} 50^{-1-}$ mice

We then investigated the phenotype of the surviving newborn cells in the DG to determine whether adult neurogenesis may be modified in the absence or presence of NF- $\kappa \mathrm{B}$ p50. For this reason, we injected an additional group $(n=5)$ of animals once daily, for 5 consecutive days, with $150 \mathrm{mg} / \mathrm{kg}$ BrdU to label a larger pool of S-phase-entering cells, and we assessed their fate 3 weeks later by double BrdU/NeuN immunofluorescence labeling. One hundred $\mathrm{BrdU}^{+}$cells were randomly selected in the granule cell layer throughout the rostrocaudal extension of the dentate gyrus of each animal. Each $\mathrm{BrdU}^{+}$cell was then analyzed in its entire $z$-axis to confirm or exclude its colabeling with the mature neuronal marker NeuN. The results showed that in 3 weeks the same percentage of BrdU-labeled cells have become mature neurons regardless of $\mathrm{p} 50$ presence. Despite no difference in the percentage of newly generated cells that become mature neurons between genotypes, in absolute numbers, as determined by multiplying the neuronal fraction by the total number of sur-

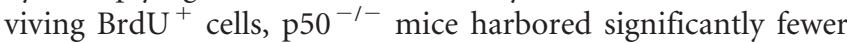
newborn neurons than wt mice (mean \pm SD, $585 \pm 143$ and $161 \pm 93$ in wt and ${\mathrm{p} 50^{-1-}}^{-1}$ mice, respectively; $p<0.01$, Student's $t$ test).

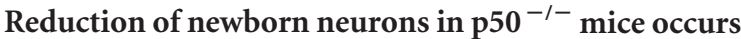 relatively late in maturation}

To determine whether some events related to neuronal maturation/differentiation in the dentate gyrus may be disrupted in the absence of NF- $\kappa \mathrm{B}$ p 50 , we used the protein marker DCX as a first indicator of neuronal determination. DCX is a microtubuleassociated protein whose expression is developmentally regulated in migrating and differentiating neurons, and that is expressed by immature neurons in the adult dentate gyrus (Brown et al., 2003). Representative images of DCX immunoreactivity in the dentate gyrus of wt and $\mathrm{p}^{-I-}$ mice are shown in Figure 3, A and $B$, respectively. Six to seven mice per experimental group were used for counting $\mathrm{DCX}^{+}$cells throughout the dentate gyrus. As shown in Figure 3E, no difference was demonstrated in the number of $\mathrm{DCX}^{+}$cells in $\mathrm{p} \mathrm{0}^{-/-}$mice compared with that of wt 

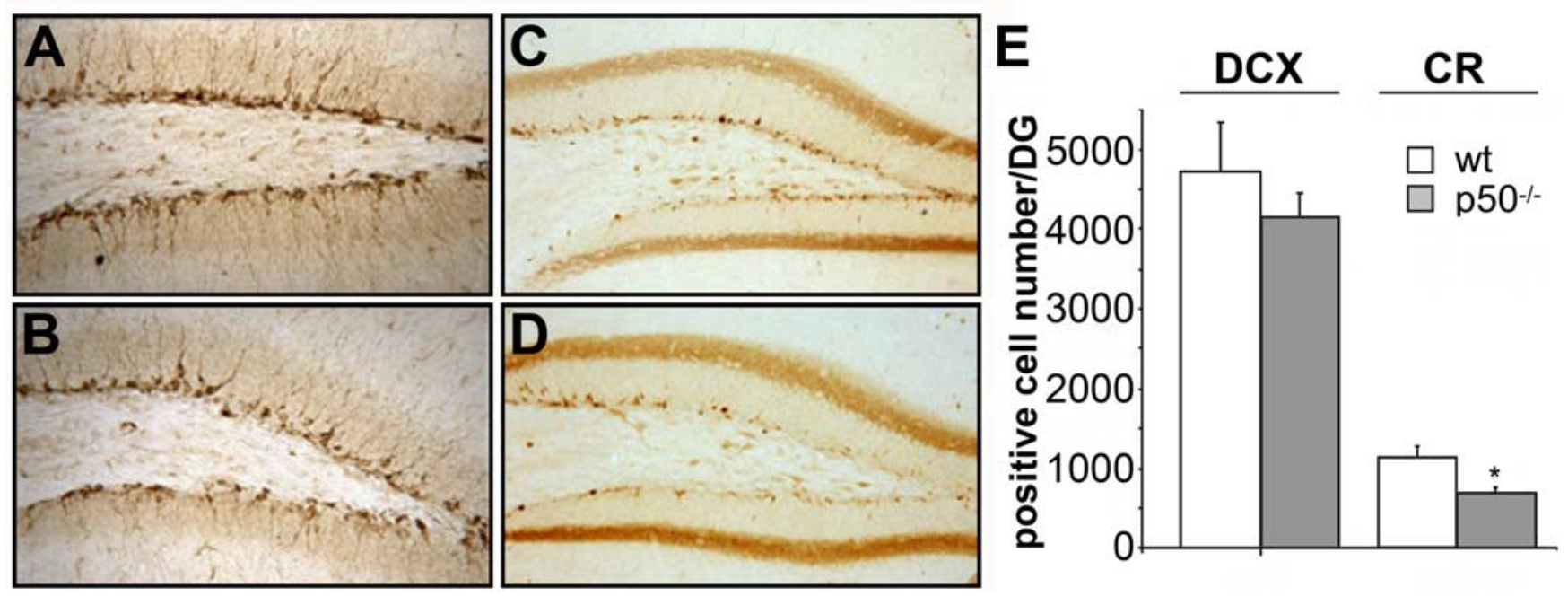

Figure 3. Reduction of newborn neurons in $\mathrm{p} 50^{-/-}$mice occurs late in maturation. $\boldsymbol{A}, \boldsymbol{B}, \mathrm{DCX}$ immunoreactivity in the dentate gyrus of wt $(\boldsymbol{A})$ and $\mathrm{p} 50^{-1-}(\boldsymbol{B})$ mice. $\boldsymbol{C}, \boldsymbol{D}$, Representative images of $C R$ immunoreactivity in the dentate gyrus of wt $(C)$ and $\mathrm{p50}^{-1-}(\boldsymbol{D})$ mice. $\boldsymbol{E}$, Total number of $\mathrm{DCX}{ }^{+}$and $\mathrm{CR}^{+}$cells in $\mathrm{DG}$ of both genotypes. Data are expressed as mean \pm SD. For each experimental group, six to seven male mice were used. ${ }^{*} p<0.05$

animals (mean \pm SD, $4720 \pm 621.7$ and $4144 \pm 308$ in wt and mutant mice, respectively). To further dissect the steps of neuronal differentiation that could be under the control of NF- $\kappa \mathrm{B}$ p50, we also examined newly generated neuronal cells in postmitotic stages, when recruitment for terminal differentiation takes place (Kempermann et al., 2004). Early postmitotic stages of adult granule cell development are characterized by the transient expression of the calcium-binding protein CR (Brandt et al., 2003). As shown in Figure $3 C-E$, a significant reduction in the number of $\mathrm{CR}^{+}$cells was observed in $\mathrm{p}^{-1-}$ mice with respect to $\mathrm{wt}$ animals (mean $\pm \mathrm{SD}$, wt, $1080 \pm 132 ; \mathrm{p} 50^{-/-}, 654.4 \pm 70$; Student's $t$ test, $p<0.05)$ suggesting that in the absence of $\mathrm{p} 50 \mathrm{a}$ reduction of newborn neurons occurs but relatively late in maturation. To confirm this hypothesis we analyzed by Western blotting the expression levels of DCX and CR in hippocampal extracts from both genotypes. Results are shown in Figure 4. Quite surprisingly, DCX level was significantly reduced $(-47 \%)$ in the mutant mice even though the number of $\mathrm{DCX}^{+}$cells did not differ in the two genotypes. A significant reduction in the level of calretinin expression $(-56 \%)$ was observed in $\mathrm{p}^{-1-}$ mice in parallel with the demonstrated reduction in the number of $\mathrm{CR}^{+}$ cells.

\section{Specific short-term memory defects without learning impairment in $\mathbf{p} 50^{-/-}$mice}

To test the physiological consequences of the observed alterations in hippocampal neurogenesis, wt and $\mathrm{p}^{-1-}$ mice were evaluated behaviorally. Initially, mice were subjected to a battery of sensorimotor tasks to reveal any difference between $\mathrm{p} 50^{-/-}$and wt mice that may confound results in learning and memory tasks. Supplemental Table 1 (available at www.jneurosci.org as supplemental material) summarizes the results obtained in the open field, beam walking, and pole tests. As previously described (Kassed and Herkenham, 2004), p50 ${ }^{-1-}$ mice showed increased exploratory behavior compared with wt animals. The Morris water maze is the most frequently used experimental paradigm to assess disturbances of cognitive functions, in particular to test spatial long-term memory and learning. Because the latency to escape onto the platform can be biased by motor ability, we also monitored swimming endurance in the two genotypes. The mean
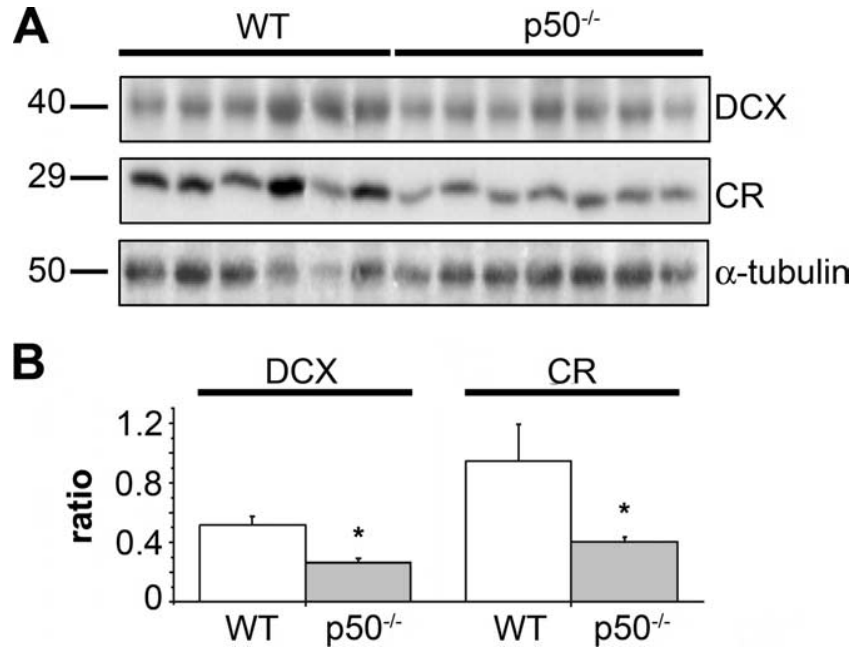

Figure 4. Expression levels of immature neuron markers $D C X$ and $C R$ are downregulated in p50 $0^{-1-}$ mice. $A, D C X, C R$, and $\alpha$-tubulin immunoblotting of protein extracts from hippocampi of six wild-type and seven $\mathrm{p}^{-1-}$ male mice, $3-4$ months of age. $\boldsymbol{B}$, Densitometric analysis of

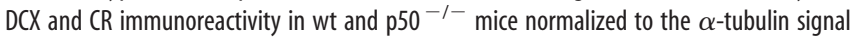
(ratio), showing a significant decrease for both proteins in mutant mice compared with wt control. Data represent mean \pm SEM of three experiments. ${ }^{*} p<0.05$.

time required for $\mathrm{p} 50^{-1-}$ mice to swim to exhaustion was significantly shorter than that of wt mice $(t=24.9$; $p<0.001)$, indicating a decreased motor performance of the mutant mice when exposed to prolonged physical effort (see supplemental Table 1, available at www.jneurosci.org as supplemental material). Despite this, when tested in the Morris water maze, wt and $\mathrm{p} 50^{-1-}$ mice performed equally. In the acquisition phase (Fig. $5 A$ ), the latency to find the hidden platform decreased gradually during trials for both $\mathrm{p}^{-1-}$ and wt mice, indicating that both genotypes were able to learn the task through training and that learning was progressive. Statistical evaluation of the acquisition phase data by one-way ANOVA indicated a significant effect of training $\left(F_{(9,261)}=6.17 ; p<0.001\right)$, no significant effect of genotype $\left(F_{(1,29)}=2.02 ; p=0.16\right)$, and no significant interaction between the two factors $\left(F_{(9,261)}=1.84 ; p=0.061\right)$. Mice visual ability was 
also similar in both genotypes as assessed by measuring the escape latency when the platform was visible (Fig. 5A). In the probe test (Fig. 5B), performed $24 \mathrm{~h}$ after the last training trial, all mice showed a target quadrant preference (one-way ANOVA, genotype, $F_{(1,29)}=0.93 ; p=0.34$; quadrant, $F_{(3,87)}=74.7 ; p<0.001$; interaction, $\left.F_{(3,87)}=0.44 ; p=0.72\right)$. The increased time spent in the target quadrant in search of the missing platform suggested normal retrieval of spatial memory in both $\mathrm{p} 50^{-1-}$ and wt mice. Mice were then subjected to the place recognition test that evaluates hippocampal-dependent short-term spatial memory by testing their ability to discriminate a familiar versus a novel environment. ANOVA indicated significant effects of genotype $\left(F_{(1,87)}=14.4 ; p<\right.$ $0.001)$ and retention interval $\left(F_{(2,87)}=\right.$ 35.3; $p<0.001)$ and a significant interaction between the two factors $\left(F_{(2,87)}=\right.$ 12.7; $p<0.001)$. Wt mice exhibited better spatial memory performance at $20 \mathrm{~min}$ $\left(F_{(1,87)}=88.1 ; p<0.001\right)$ and $30 \min \left(F_{(1,87)}=98.7 ; p<0.001\right)$ retention intervals. As shown in Figure $6 A$, Wilcoxon test $(p<$ 0.05 ) supported these results with wt mice tested at 20 and $30 \mathrm{~min}$ retention intervals entering the novel arm more frequently than the familiar arms. Conversely, when tested at $40 \mathrm{~min}$ retention interval, the animals entered the novel and familiar arm similarly $\left(F_{(1,87)}=0.02 ; p=0.89\right)$. Therefore, in our experimental conditions, the memory for the environment in wt mice lasted $>30$ min but $<40$ min. p50 ${ }^{-1-}$ mice exhibited better spatial memory performance at $20 \mathrm{~min}$ retention interval $\left(F_{(1,87)}=65.9 ; p<\right.$ 0.001 ) (Fig. 6C). These data are supported by the observation that at 20 min retention interval, $\mathrm{p} 50^{-l-}$ mice entered the novel arm more than the familiar arm (Fig. $6 B)(p<0.05$, Wilcoxon test). In contrast, when tested at 30 and 40 min retention intervals, they entered the novel and familiar arms similarly $\left(F_{(1,87)}=0.92 ; p=\right.$ 0.34 and $F_{(1,87)}=0.42 ; p=0.51$, respectively). Therefore, in our experimental conditions, the memory for the environment in p50 $0^{-1-}$ mice lasted $>20 \mathrm{~min}$ but $<30 \mathrm{~min}$. According to these results, compared with wt mice, $\mathrm{p} 50^{-1-}$ mice have an impairment in short-term spatial memory (Fig. 6C) (30 min retention interval, wt vs ${\mathrm{p} 50^{-1-}}^{-1}$ mice, $p<0.05$, LSD post hoc test).

\section{Discussion}

We previously demonstrated that distinct NF- $\kappa$ B members are present in specific cell populations of the SVZ, one of the neurogenic regions of the adult brain, suggesting that this transcription factor family may be involved in postnatal neurogenesis (DenisDonini et al., 2005). In this study, we extend our previous observations by evaluating the proliferation and maturation of newly generated progenitors in the adult hippocampus of $\mathrm{NF}-\kappa \mathrm{B}$ p50 ${ }^{-1-}$ mice. We demonstrated through BrdU labeling and Ki67 antigen expression that the rate of proliferation within the dentate gyrus was not significantly different between $\mathrm{p} 0^{-1-}$ and wt mice. These data were confirmed also in vitro, because no difference was observed in the proliferation rate of neural stem cells derived from the hippocampi of wt and $\mathrm{p} 50^{-1-}$ mice. On the contrary, the late survival of newborn $\mathrm{BrdU}^{+}$cells was drastically

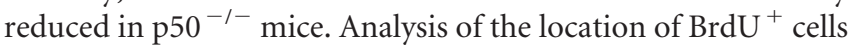
in the different subregions of the dentate gyrus showed that there was a statistically significant reduction in the number of $\mathrm{BrdU}^{+}$ cells in the granular cell layer and in the hilus but not in the subgranular zone, possibly suggesting a more pronounced effect of p50 absence in regions where newly generated cells migrate and differentiate than in the SGZ, which includes progenitors, part of which remain BrdU positive. When we characterized the cell populations that are affected by the absence of NF- $\kappa \mathrm{B}$ p 50 , we observed no difference in the number of $\mathrm{DCX}^{+}$cells but a marked reduction of $\mathrm{CR}^{+}$cells in the dentate gyrus of mutant mice. Quite surprisingly, although the number of DCX ${ }^{+}$cells was similar in both genotypes, the expression level of DCX was drastically reduced in mutant mice. The level of CR expression was also reduced, but this change paralleled the reduced number of CR-positive cells. We exclude that changes in protein expression may represent a simple consequence of DCX and CR being $\mathrm{NF}-\kappa \mathrm{B}$ target genes, because similar expression levels for both proteins in the olfactory bulbs of wt and $\mathrm{p}^{-1-}$ mice (data not shown) argue against this possibility. When neurogenesis was evaluated, the same fraction of $\mathrm{BrdU}^{+}$cells coexpressed the neuronal marker $\mathrm{NeuN}$ in both genotypes, suggesting that overall cell fate is not altered in the mutant mice, although, in absolute numbers, they harbor significantly fewer new neurons than wt mice. Altogether, these results suggest highly selective defects in adult neurogenesis in the absence of $\mathrm{p} 50$ protein, possibly occurring at the transition between the maturation stages marked by the expression of DCX and CR. The best characterized functional role of DCX is in the regulation of radial migration (Corbo et al., 2002; Bai et al., 2003), but no overt migratory defects were observed in the dentate gyrus of $\mathrm{p} 50^{-1-}$ mice. Walker et al. (2007) recently suggested that $\mathrm{DCX}^{+}$cells may represent a heterogenous population, including high- and low-DCX-expressing cells. These authors proposed that the $\mathrm{DCX}^{\text {(high) }}$ cells are restricted to the neuronal lineage or are bona fide neurons, whereas some $\mathrm{DCX}^{\text {(low) }}$ cells retain their multipotentiality. We cannot exclude that the reduced level of DCX expression may underlie a phenotypic switch of DCX-expressing cells toward the less committed cell population. We also investigated the overlap between hippocampal DCX and CR expression by double immunofluorescence to gain further insight into the changes occurring at the transition 

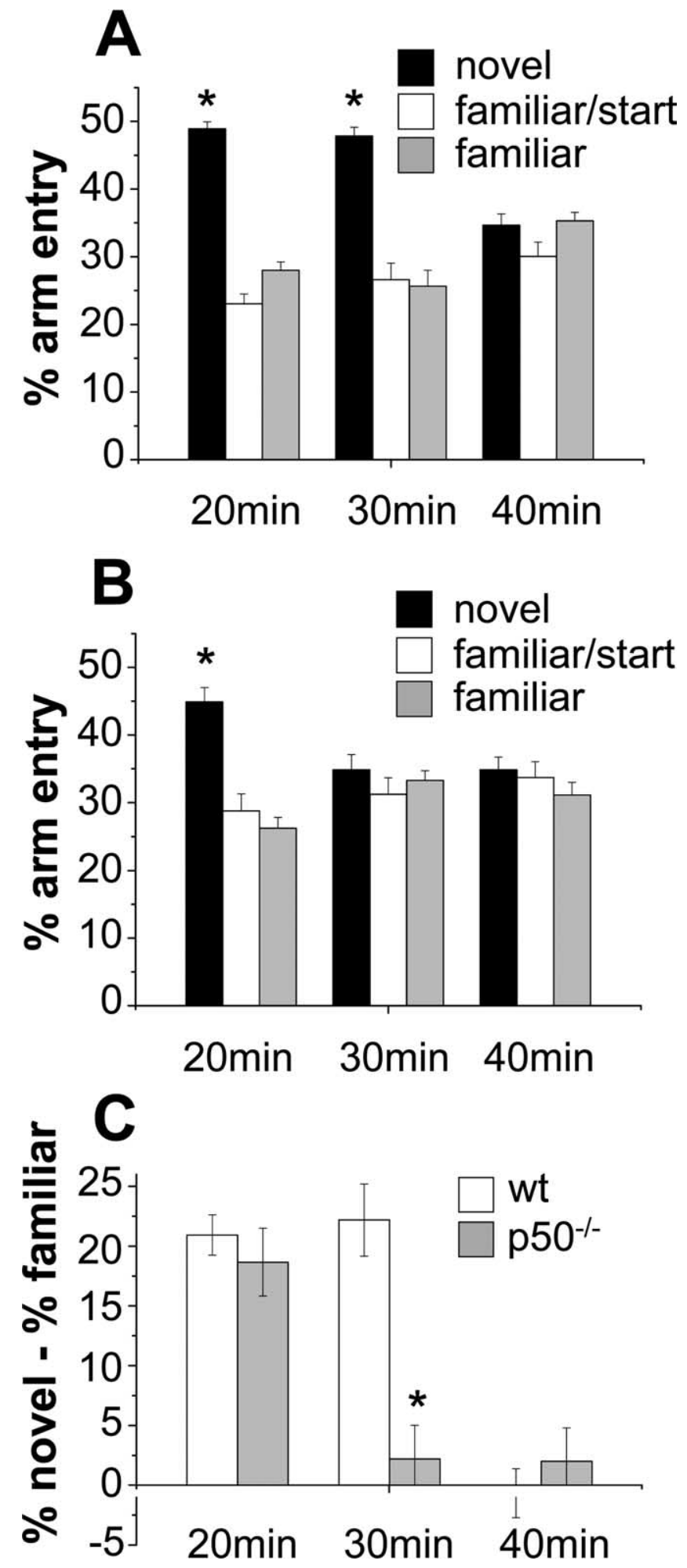

Figure 6. $\mathrm{p50} 0^{-1-}$ mice exhibit a deficit in a hippocampal-dependent task requiring spatial short-term memory. Effect of different retention intervals on spatial memory performance of p50 ${ }^{-1-}$ and wt mice in the place recognition test. $A$, Wt mice, tested at 20 and 30 min retention intervals, entered the novel arm more frequently than the other arms, and when tested at 40 min entered the novel and other arms similarly. $B, \mathrm{p} 50^{-1-}$ mice tested at 20 min retention interval entered more frequently the novel arm than the others, but when tested at 30 and 40 min entered the novel and other arms similarly. $\boldsymbol{C}$, Differences in spatial memory between the

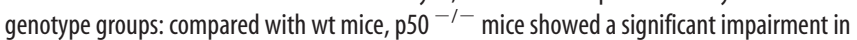
short-term spatial memory. ${ }^{*} p<0.05$. between DCX and CR expression. No difference was observed in the morphology and the proportion of double-labeled $\mathrm{DCX}^{+} /$ $\mathrm{CR}^{+}$versus single $\mathrm{CR}^{+}$cells in wt versus $\mathrm{p}^{+} 0^{-/-}$mice (data not shown), suggesting that both $\mathrm{DCX}^{+} / \mathrm{CR}^{+}$and $\mathrm{DCX}^{-} / \mathrm{CR}^{+}$subpopulations are diminished in the mutant compared with control mice.

We evaluated the occurrence of hippocampal neurodegeneration in $\mathrm{p}^{-1-}$ mice because degenerative changes were described by Lu et al. (2006) in the cortex and hippocampus of 6- to 10 -month-old female $\mathrm{p}^{-1-}$ mice. In our experimental setting, we used only 3- to 4-month-old male mice, and we did not observe any morphological sign of neurodegeneration at this age or at later ages (data not shown). At this stage, we cannot explain these discrepancies unless the age-dependent degenerative changes observed by $\mathrm{Lu}$ are sex related. Interestingly, astroglial $\mathrm{NF}-\kappa \mathrm{B}$ has been shown to regulate synaptic plasticity in female but not male mice (Bracchi-Ricard et al., 2007).

Thousands of neurons are generated each week in the dentate gyrus, but the majority die within 1 month, when the integration into functional networks represents the final selection for survival (Biebl et al., 2000; Kempermann et al., 2003; Lehmann et al., 2005). However, the marked reduction in late survival of new-

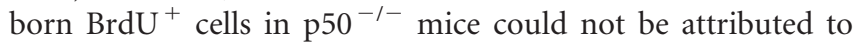
increased apoptosis, as measured by TUNEL staining. The apparent paradox of reduced $\mathrm{BrdU}^{+}$cell survival in absence of increased cell death is quite intriguing. The homeostatic mechanisms that regulate neuron addition to neuronal networks in adulthood are largely unknown. It is not clear whether in the hippocampus newly generated neurons may be preferentially substituted by more recently generated neurons or if addition of new neurons is in part balanced by loss of old neurons (Lehmann et al., 2005; Ninkovic et al., 2007). Given the complex role of NF-kappaB family members in regulating cell death and/or survival (Grilli et al., 1996; Mattson and Camandola, 2001; Meffert and Baltimore, 2005), one exciting possibility is that in $\mathrm{p}^{-1-}$ mice the minor insertion of new neurons into preexisting circuits may be counterbalanced by a reduced elimination rate of older mature neurons.

The functional contribution of adult neurogenesis to the neuronal network remains also largely unknown. Several groups have reported data correlating alterations in neurogenesis with deficit/enhancement in learning and memory performance (Gould et al., 1999; van Praag et al., 1999; Shors et al., 2001; Kempermann, 2002; Aimone et al., 2006; Leuner et al., 2006; Kee

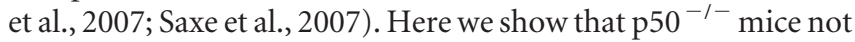
only exhibit specific deficits in net adult hippocampal neurogenesis but also a specific impairment in a hippocampal-dependent task of short-term spatial memory. We do not attempt to imply that a cause-effect relationship between neurogenesis defects and selective deficits in short-term spatial memory may exist in p $50^{-1-}$ mice, but certainly the correlation between these phenomena deserves further investigation. Indeed, the preferential incorporation of adult-generated granule cells into spatial memory networks has been suggested (Kee et al., 2007). Recently, Dupret et al. (2007) have proposed that spatial learning requires both addition and removal of the newly generated neurons, providing evidence of an even more complex mechanism contributing to memory formation in mammals. The specific role of $\mathrm{NF}-\kappa \mathrm{B}$ proteins and in particular of $\mathrm{p} 50$ in regulating expression of genes involved in selection of newly generated neurons or in synaptic plasticity should be further pursued. Young granule neurons differ substantially from neighboring mature granule cells because they exhibit special properties in synaptic plasticity, 
such as a lower threshold for the induction of long-term potentiation (Wang et al., 2000; Schmidt-Hieber et al., 2004). This enhanced synaptic plasticity appears to be present in cells at the late DCX phase, which means at the transition between the maturation stages that we believe to be altered in the $\mathrm{p} 50^{-1-}$ mice. Such a property seems to be very important for some forms of hippocampal-dependent learning and memory (Song et al., 2005). Despite reduced short-term spatial memory in the mutant mice, when the Morris water maze was used to test hippocampusdependent learning, including acquisition of long-term spatial memory, $\mathrm{p} 50^{-1-}$ and wt mice performed equally, demonstrating no learning impairment and also intact long-term memory in absence of $\mathrm{p} 50$ protein. Mice deficient for other NF- $\kappa \mathrm{B}$ subunits have been shown to exhibit deficits in specific cognitive tasks (Levenson et al., 2004; Meffert and Baltimore, 2005; Kaltschmidt et al., 2006; O'Mahony et al., 2006), although no correlation has ever been attempted with adult neurogenesis. Targeted disruption of the NF- $\kappa \mathrm{B} 1$ gene should have profound consequences on the pool of dimeric NF- $\kappa \mathrm{B}$ complexes because p 50 homodimers, but also p50-p65 heterodimers, as well as any other p50containing heterodimer, are not formed in mutant mice. The

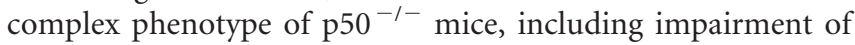
short-term spatial memory but intact learning and long-term memory, may in part result from these complex changes.

Several neurodegenerative disorders have also been associated with alterations in both neurogenesis (Steiner et al., 2006) and NF- $\kappa$ B-mediated transcription (Grilli and Memo, 1999; Memet, 2006; Camandola and Mattson, 2007), but no attempt has been made to correlate these phenomena. In particular, several groups have reported dysregulated expression/activation of NF- $\kappa \mathrm{B}$ proteins and, in some cases, specific alterations in p50 signaling in disorders such as Alzheimer's disease, Parkinson's disease, and Huntington's disease. Whether or not these alterations may contribute to altered neurogenesis described in such disorders remains to be investigated. Additionally, alterations in NF- $\kappa \mathrm{B}$ signaling, including p50 expression/activation, have been reported during aging in the hippocampus (Toliver-Kinsky et al., 1997). It would be of interest to evaluate whether these alterations may also potentially contribute to age-dependent changes in the neurogenic potential.

\section{References}

Aimone JB, Wiles J, Gage FH (2006) Potential role for adult neurogenesis in the encoding of time in new memories. Nat Neurosci 9:723-727.

Bai J, Ramos RL, Ackman JB, Thomas AM, Lee RV, LoTurco JJ (2003) RNAi reveals doublecortin is required for radial migration in rat neocortex. Nat Neurosci 6:1277-1283.

Biebl M, Cooper CM, Winkler J, Kuhn HG (2000) Analysis of neurogenesis and programmed cell death reveals a self renewing capacity in the adult rat brain. Neurosci Lett 291:17-20.

Bracchi-Ricard V, Brambilla R, Levenson J, Hu W-H, Bramwell A, Sweatt JD, Green EJ, Bethea JR (2007) Astroglial nuclear factor-kappaB regulates learning and memory and synaptic plasticity in female mice. J Neurochem 104:611-623.

Brandt MD, Jessberger S, Steiner B, Kronenberg G, Reuter K, Bick-Sander A, von der Behrens W, Kemperman G (2003) Transient calretinin expression defines early postmitotic step of neuronal differentiation in adult hippocampal neurogenesis of mice. Mol Cell Neurosci 24:603-613.

Brown JP, Couillard Després S, Cooper-Kuhn CM, Winkler J, Aigner L, Kuhn HG (2003) Transient expression of doublecortin during adult neurogenesis. J Comp Neurol 467:1-10.

Camandola S, Mattson MP (2007) NF-kappaB as a therapeutic target in neurodegenerative diseases. Expert Opin Ther Targets 11:123-132.

Corbo JC, Deuel TA, Long JM, LaPorte P, Tsai E Wynshaw-Boris A, Walsh CA (2002) Doublecortin is required in mice for lamination of the hippocampus but not the neocortex. J Neurosci 22:7548-7557.
Denis-Donini S, Caprini A, Frassoni C, Grilli M (2005) Members of the NF-kappaB family expressed in zones of active neurogenesis in the postnatal and adult mouse brain. Dev Brain Res 154:81-89.

Denk A, Wirth T, Bauman B (2000) NF-kappaB transcription factors: critical regulators of hematopoiesis and neuronal survival. Cytokine Growth Factor Rev 11:303-320.

Dupret D, Fabre A, Dobrossy MD, Panatier A, Rodriguez AP, Lamarque S, Lemaire V, Oliet SHR, Piazza PV, Abrous DN (2007) Spatial learning depends on both the addition and removal of new hippocampal neurons. PLOS Biol 5:1683-1694.

Gould E, Tanapat P, Hastings NB, Shors TJ (1999) Neurogenesis in adulthood: a possible role in learning. Trends Cogn Sci 3:186-192.

Grilli M, Memo M (1999) NF-kappaB/Rel proteins: a point of convergence of signalling pathways relevant in neuronal function and dysfunction. Biochem Pharmacol 57:1-7.

Grilli M, Pizzi M, Memo M, Spano PF (1996) Neuroprotection by aspirin and sodium salicylate through blockade of NF-kappaB activation. Science 274:1383-1385.

Kaltschmidt B, Ndiaye D, Corte M, Pothion S, Arbibe L, Prullage M, Pfeiffer J, Lindecke A, Staiger V, Israël A, Kaltschmidt C, Mémet S (2006) NFkappaB regulates spatial memory formation and synaptic plasticity through protein kinase A/CREB signalling. Mol Cell Biol 26:2936-2946.

Kassed CA, Herkenham M (2004) NF-kappaB p50 deficient mice show reduced anxiety-like behavior in tests of exploratory drive and anxiety. Behav Brain Res 154:577-584.

Kee N, Teixairan CM, Wang AH, Frankland PW (2007) Preferential incorporation of adult-generated granule cells into spatial memory networks in the dentate gyrus. Nat Neurosci 10:355-362.

Kempermann G (2002) Why new neurons? Possible functions for adult hippocampal neurogenesis. J Neurosci 22:635-638.

Kempermann G, Kuhn HG, Gage FH (1997) More hippocampal neurons in adult mice living in an enriched environment. Nature 386:493-495.

Kempermann G, Gast D, Kronenberg G, Yamaguchi M, Gage FH (2003) Early determination and long-term persistence of adult-generated new neurons in the hippocampus of mice. Development 130:391-399.

Kempermann G, Jessberger S, Steiner B, Kronenberg G (2004) Milestones of neuronal development in the adult hippocampus. Trends Neurosci 27:447-452.

Lehmann K, Butz M, Teuchert-Noodt G (2005) Offer and demand: proliferation and survival of neurons in the dentate gyrus. Eur J Neurosci 21:3205-3216.

Leuner B, Gould E, Shors TJ (2006) Is there a link between adult neurogenesis and learning? Hippocampus 16:216-224.

Levenson JM, Choi S, Lee S-Y, Cao YA, Ahn HJ, Worley KC, Pizzi M, Liou H, Sweat JD (2004) A bioinformatic analysis of memory consolidation reveals involvement of the transcription factor c-rel. J Neurosci 24:3933-3943.

Lu ZY, Yu SP, Wei JF, Wei L (2006) Age related neural degeneration in nuclear factor kappaB p50 knockout mice. Neuroscience 139:965-978.

Mattson MP, Camandola S (2001) NF-kappaB in neuronal plasticity and neurodegenerative disorders. J Clin Invest 107:247-254.

Mattson MP, Meffert MK (2006) Roles for NF-kappaB in nerve cell survival, plasticity, and disease. Cell Death Diff 13:852-860.

Meffert MK, Baltimore D (2005) Physiological functions for brain NFkappaB. Trends Neurosci 28:37-43.

Memet S (2006) NF-kappaB functions in the nervous system: from development to disease. Biochem Pharmacol 72:1180-1195.

Ninkovic J, Mori T, Gotz M (2007) Distinct modes of neuron addition in adult mouse neurogenesis. J Neurosci 27:10906-10911.

O’Mahony A, Raber J, Montano M, Foehr E, Han V, Lu S, Kwon H, LeFevour A, Chakraborty-Sett S, Greene WC (2006) NF-kappaB/Rel regulates inhibitory and excitatory neuronal function and synaptic plasticity. Mol Cell Biol 26:7283-7298.

Saxe MD, Malleret G, Vronskaya S, Mendez I, Garcia AD, Sofroniew MV, Kandel ER, Hen R (2007) Paradoxical influence of hippocampal neurogenesis on working memory. Proc Natl Acad Sci USA 104:4642-4646.

Schmidt-Hieber C, Jonas P, Bischofberger J (2004) Enhanced synaptic plasticity in newly generated granule cells of the adult hippocampus. Nature 429:184-187. 
Scholtzen T, Gerdes J (2000) The Ki-67 protein: from the known and the unknown. J Cell Physiol 182:311-322.

Seri B, Garcia-Verdugo JM, McEwen BS, Alvarez-Buylla A (2001) Astrocytes give rise to new neurons in the adult mammalian hippocampus. J Neurosci 21:7153-7160.

Seri B, Garcia-Verdugo JM, Collado-Morente L, McEwen BS, Alvarez-Buylla A (2004) Cell types, lineage, and architecture of the germinal zone in the adult dentate gyrus. J Comp Neurol 478:359-378.

Sha WC, Liou HC, Tuomanen EI, Baltimore D (1995) Targeted disruption of the p50 subunit of NF-kappaB leads to multifocal defects in immune responses. Cell 80:321-330.

Shors TJ, Miesagaes G, Beylin A, Zhao M, Rydel T, Gould E (2001) Neurogenesis in the adult is involved in the formation of trace memories. Nature 410:372-376.

Song H, Kempermann G, Overstreet Wadiche L, Zhao C, Schinder AF, J Bischofberger (2005) New neurons in the adult mammalian brain: synaptogenesis and functional integration. J Neurosci 25:10366-10368.
Steiner B, Wolf SA, Kempermann G (2006) Adult neurogenesis and neurodegenerative diseases. Regenerative Med 1:15-28.

Toliver-Kinsky T, Papaconstantinou J, Perez-Polo JR (1997) Age-associated alterations in hippocampal and basal forebrain nuclear factor kappa B activity. J Neurosci Res 48:580-587.

van Praag H, Christie BR, Sejnowski TJ, Gage FH (1999) Running enhances neurogenesis, learning, and long-term potentiation in mice. Proc Natl Acad Sci USA 96:13427-13431

Walker TL, Yasuda T, Adams DJ, Bartlett PF (2007) The doublecortinexpressing population in the developing and adult brain contains multipotential precursors in addition to neuronal-lineage cells. J Neurosci 27:3734-3742.

Wang S, Scott BW, Wojtowicz JM (2000) Heterogenous properties of dentate granule neurons in the adult rat. J Neurobiol 42:248-257.

West MJ (1999) Stereological methods for estimating the total number of neurons and synapses: issues of precision and bias. Trends Neurosci 22: $51-61$. 